\title{
Phonological priming: Failure to replicate in the rapid naming task
}

\author{
MIRA PETER \\ University of Connecticut, Storrs, Connecticut \\ and Haskins Laboratories, New Haven, Connecticut \\ GEORGIJE LUKATELA \\ University of Belgrade, Belgrade, Yugoslavia \\ and \\ M. T. TURVEY \\ University of Connecticut, Storrs, Connecticut \\ and Haskins Laboratories, New Haven, Connecticut \\ (Leonard Katz, Sponsor)
}

\begin{abstract}
In two experiments, we examined the use of phonological information in naming in English. In both experiments, a priming technique was used. Primes and targets were both graphemically and phonemically similar, only phonemically similar, or unrelated. The results of Experiment 1 did not reveal a significant priming effect. The same design and materials were used in Experiment 2, but this time, the context was forward masked. Again, the results of Experiment 2 showed no existence of a phonological priming effect. These negative outcomes extend the failure of Martin and Jensen (1988) to obtain rhyming effects in the lexical decision task with English words, and they are contrary to recent investigations with Serbo-Croatian words (Lukatela \& Turvey, 1990).
\end{abstract}

Using the lexical decision task, Hillinger (1980) showed an effect of phonemic priming independent of the graphemic similarity between the prime and the target. In more recent experiments, however, Martin and Jensen (1988) found no evidence of phonological facilitation with either graphemically similar or graphemically dissimilar primetarget word pairs. In the present article, we pursue the possibility that phonological priming effects should be more apparent when the dependent measure is rapid naming rather than lexical decision. Intuitively, naming is more dependent on phonological information than lexical decision is; consequently, rhyming effects should be more evident in naming. Our motivation for doing so is the fact that phonological priming effects are strongly present in Serbo-Croatian, under conditions of both lexical decision and naming (Lukatela \& Turvey, 1990). The contrasting negative results of Martin and Jensen (1988) with English could be indicative of processing differences that are due to orthographic differences in the two languages (Lukatela \& Turvey, 1990; Lukatela, Feldman, Turvey, Carrelo, \& Katz, 1989; Lukatela, Turvey, Feldman, Carrelo, \& Katz, 1989). In contrast with English, Serbo-Croatian has a phonemically precise orthography (one-to-one mapping of letters and phonemes), and in Serbo-Croatian, the

This research was supported in part by National Institute of Child Health and Human Development Grants HD-08495 and HD-01994 to the University of Belgrade and Haskins Laboratories, respectively. Requests for reprints may be sent to M. T. Turvey, Haskins Laboratories, 270 Crown Street, New Haven, CT 06511. recognition of words may depend on phonological information more than is the case in English. Phonological priming or rhyming effects in English have not, however, been evaluated with naming. In the absence of this evaluation, comparisons between the two languages in terms of sensitivity to phonological priming are restricted.

\section{EXPERIMENT 1}

In the present experiment, we tried to replicate the effect of phonological priming reported by Hillinger (1980), but with naming as the dependent measure. Word frequency was introduced, because of Columbo's (1986) observation in the lexical decision task of an inhibitory effect for high-frequency priming pairs and a facilitatory effect for low-frequency priming pairs. This dependence of the direction of the rhyming effect on frequency was similarly observed by Lukatela and Turvey (1990) for lexical decision but not for naming. Since frequency was not a variable in Hillinger's experiments, only a part of his stimulus set was used in our replication; other stimuli had to be introduced to provide the required frequency variation and control.

\section{Method}

Subjects. Sixty college students participated in the experiment, as part of their laboratory requirements. They were given partial course credit. The subjects were assigned to one of the four counterbalancing groups according to the order in which they appeared at the testing room.

Materials. A pool of 88 rhyming word-word pairs was used in the experiment. Half of the pairs were both graphemically and phonemically similar, and half were only phonemically similar. In each group 
(condition), half of the pairs had high-frequency targets, with a mean frequency of 246.36 per million (Kucera \& Francis, 1967), and half had low-frequency target words, with a mean frequency of 14.6. All target words were between 4 and 6 letters long. In each frequency set, four situations were established according to the type of context. Each target word was preceded by four different types of context: (1) both graphemically and phonemically similar context word (e.g., late-mate, (2) unrelated word control (e.g., table-mate), (3) phonemically similar but graphemically dissimilar word (e.g., eight-mate), and (4) neutral control (e.g., and-mate). The situation with the neutral control prime had been shown not to be significantly different from that for unrelated word controls in previous research (Hillinger, 1980). However, instead of using a nonlexical prime (a row of xs) as Hillinger did, a lexical item, namely, the word and, was used. Using the word and as a neutral control has the advantage over a row of Xs; and is a lexical prime. But as de Groot, Thomassen, and Hudson (1982) reported, a disadvantage might occur-namely, that when a word such as and is used as a neutral control, it might produce a systematic facilitation compared to word-word pairs. Some of Hillinger's word-word pairs were used, but to control for target frequency, other different pairs were constructed. Eighty-eight pseudoword targets were derived from the word targets by changing, deleting, or adding a letter to targets while retaining both graphemically and phonologically legitimate letter strings (e.g., late-vate for Type 1, table-vate for Type 2, eight-vate for Type 3, and and-vate for Type 4).

Design. Each subject saw a given target only once, preceded by one of the context types. A given context was seen twice by each subjectonce preceding the word target, and once preceding the pseudoword target. Thus, every subject saw every type of pair $(1,2,3,4)$, and every target appeared in every type of pair. Each subject saw 176 randomly ordered experimental stimulus pairs ( 80 word targets, 80 nonword targets, and 16 filler items). There were 32 practice trials of the same type of preceding the experimental trials.

Procedure. Each subject was tested individually. The subject was seated in front of the Apple Ile computer in a quiet testing room. A fixation point was centered on the screen. Before each trial, the subject heard a short warning signal. Immediately after the signal, a word appeared for $500 \mathrm{msec}$ above the fixation point. After a 100 -msec interstimulus interval, a letter string appeared below the fixation point for $500 \mathrm{msec}$. The subject was instructed to read aloud, as rapidly and as accurately as possible, the second string. To ensure that subjects were paying attention to the context, they were asked from time to time, by a computer prompt, to report the identity of the immediately preceding word pair. Latencies were measured from the onset of the target to the onset of the response, with a voice-operated trigger. If the response did not occur within $1,400 \mathrm{msec}$, it was considered an error. When the pronunciation was incorrect or not smooth, the naming was also considered to be erroneous. The interval between successive trials was $2,500 \mathrm{msec}$. There was a brief rest between the practice trials, between the experimental trials, and following each quarter of the experimental trials. Each experimental quarter was preceded by four warm-up trial pairs.

\section{Results}

The cutoff points for naming latencies were set at 250 and $2,000 \mathrm{msec}$, respectively. All the responses out of this range were considered to be errors. The mean latencies (with standard deviations) and percent errors are presented at Table 1.
A three-way analysis of variance was performed, with the factors as type of context, target frequency, and lexicality. The main effect of type of context was not significant in the overall analysis $\left[\min F^{\prime}(3,670)=1.94, p<\right.$ $.121]$. The factors of target frequency $\left[\min F^{\prime}(1,202)=\right.$ $8.09, p<.005]$ and lexicality $\left[\min F^{\prime}(1,230)=113.29\right.$, $p<.001]$ were significant. None of the interactions revealed significance. Since the lexicality factor was significant, separate analyses of variance were conducted for both words and pseudowords. In the words analysis, none of the main effects or interactions were significant. For pseudowords, both type of context $\left[\min F^{\prime}(3,364)=2.86\right.$, $p<.037]$ and frequency $\left[\min F^{\prime}(1,221)=6.42, p<\right.$ $.012]$ were significant. Post hoc analysis for pseudowords revealed significant differences for both graphemically similar and phonemically similar pairs compared with unrelated controls $\left[\min F^{\prime}(1,70)=4.21, p<.04\right]$. Both high- and low-frequency rhyming pseudoword targets were named faster than control pseudoword targets were. The difference between the two experimental conditions was not significant.

For the analysis of variance on the error data, only lexicality proved significant $\left[\min F^{\prime}(1,117)=26.04, p<\right.$ $.001]$. Separate partial analysis was also conducted using two experimental conditions and only one of the controls at a time, but none of the factors turned out to be significant in either analysis. There was no significant difference between the two types of controls.

Experiment 1 was intended to test whether or not the rhyming facilitation found by Hillinger (1980) in the lexical decision task also exists in the naming task. Because phonological information seems necessary for naming, it was expected that phonological priming would occur. The experiment failed to provide evidence for either a phonological or a graphemic similarity effect, in replication of Martin and Jensen's (1988) results in English with the lexical decision task, and in contrast with the results of Lukatela and Turvey (1990) for both the lexical decision and the naming tasks.

\section{EXPERIMENT 2}

The second experiment replicated the first, but a forward masking procedure was added. There are at least three reasons why forward masking is to be recommended for the graphemic/phonological priming paradigm. The most important is the empirical observation that only under masking conditions does the graphemic priming effect with

Table 1

Mean Naming Latencies (in Milliseconds), Standard Deviations, and Error Rate as a Function of Lexicality and Frequency in Experiment 1

\begin{tabular}{|c|c|c|c|c|c|c|c|c|c|c|c|c|}
\hline \multirow[b]{3}{*}{ Condition } & \multicolumn{6}{|c|}{ Words } & \multicolumn{6}{|c|}{ Pseudowords } \\
\hline & \multicolumn{3}{|c|}{ High-Frequency } & \multicolumn{3}{|c|}{ Low-Frequency } & \multicolumn{3}{|c|}{ High-Frequency } & \multicolumn{3}{|c|}{ Low-Frequency } \\
\hline & $M$ & $S D$ & $\%$ Error & $M$ & $S D$ & $\%$ Error & $M$ & $S D$ & $\%$ Error & $M$ & $S D$ & $\%$ Error \\
\hline 1 & 555 & 78 & 3.54 & 564 & 74 & 2.16 & 604 & 84 & 6.47 & 625 & 90 & 6.78 \\
\hline 2 & 553 & 73 & 2.47 & 569 & 77 & 3.24 & 625 & 94 & 7.40 & 647 & 85 & 10.17 \\
\hline 3 & 554 & 76 & 2.47 & 565 & 76 & 2.62 & 614 & 85 & 5.86 & 635 & 90 & 6.63 \\
\hline 4 & 548 & 75 & 3.08 & 559 & 77 & 2.16 & 620 & 94 & 6.93 & 642 & 94 & 6.93 \\
\hline
\end{tabular}


English materials occur consistently in lexical decision tasks (Evett \& Humphreys, 1981; Forster \& Davis, 1984; Humphreys, Evett, \& Taylor, 1982; Humphreys, Evett, Quinlan, \& Besner, 1987). It is not clear why this is the case, but it has been shown repeatedly that under masking, form priming is strong; without masking, it is weak or nonexistent. The existence of a priming effect when subjects have difficulty identifying the prime suggests that such effects might arise automatically and are not under the influence of the subject's intentional usage of the prime. Another important reason for using a masking procedure is theoretical. When discussing the nature and processes involved in form priming without masking, possible priming effects could be due to letter repetition or episodic memory traces. If visual characteristics of the prime are destroyed (more or less) by the mask, and if episodic memory traces are unable to play a significant role, then an observed priming effect must be due to some fundamental (and perhaps more abstract) commonality between a prime and a target-one that is realized automatically, independently of visual aspects. To be more precise, if there is no easily identifiable visual similarity between the prime and the target, and if priming occurs for phonemically similar pairs of words, then the most probable source of the effect is phonemic similarity. The same argument may be viewed from a different perspective. If visual (graphemic) similarity is obscuring a true phonemic priming effect, then, when this obstruction is removed, a phonemic priming effect should be observed.

\section{Method \\ Subjects. Eighty college students participated in Experiment 2 as part of their laboratory requirements. The subjects were assigned to one of the four groups according to the order in which they appeared at the testing room. \\ Materials. The stimulus pairs were those used in Experiment 1. The design and procedure were as those in Experiment 1, except for the du- ration of the stimuli and the addition of a forward mask. After the short warning signal, a mask (a row of hash marks) appeared on the screen for $500 \mathrm{msec}$. Immediately after the mask, a prime appeared for $150 \mathrm{msec}$ in the same location, and immediately after the prime, a target letter string appeared for $300 \mathrm{msec}$ in the same place. There was no interstimulus in- terval between either the mask and the prime or the prime and the target. All other parameters remained the same as in Experiment 1.}

\section{Results}

The results of the analysis are presented in Table 2 . The cutoff points for naming latencies occurred at $250 \mathrm{msec}$ and 2,000 msec, respectively. A three-way analysis of variance was performed, with the factors again type of con- text, target frequency, and lexicality. The main effect of type of context was significant $\left[\min F^{\prime}(3,687)=9.92, p\right.$ $<.001]$, as were the factors of target frequency $\left[\min F^{\prime}(1,201)=14.09, p<.001\right]$ and lexicality $\left[\min F^{\prime}(1,247)=156.27, p<.001\right]$. None of the interactions were significant, although in the analysis by subjects all the interactions with the factor of lexicality were significant. Separate two-way ANOVAs were conducted for words and pseudowords, respectively. In the analysis for words, there was no significant difference between high- and low-frequency targets. The main effect of type of prime was significant for both high- $\left[\min F^{\prime}(3,202)=\right.$ $4.37, p<.005]$ and low-frequency words $\left[\min F^{\prime}(3,181)\right.$ $=5.41, p<.001]$. The significance of type of prime was obtained only when experimental groups were compared with the neutral prime and [for high-frequency words, $\min F^{\prime}(2,142)=5.35, p<.002$, and low-frequency words, $\left.\min F^{\prime}(2,126)=7.65, p<.001\right]$. In the analysis in which the unrelated prime condition served as the baseline, none of the factors turned out to be significant. The difference between the two control groups was significant for both high- $\left[\min F^{\prime}(1,590)=5.7, p<.020\right]$ and lowfrequency words $\left[\min F^{\prime}(1,60)=11.1, p<.001\right]$. There was no significant difference between the two experimental conditions.

In the analysis for pseudowords, the target-frequency factor was significant $\left[\min F^{\prime}(91,206)=14.92, p<.001\right]$. The type of prime was significant only for high-frequency pseudowords [ $\left.\min F^{\prime}(3,192)=3.81, p<.011\right]$. In the post hoc analysis, the only significant differences were found between the two control conditions $\left[\min F^{\prime}(1,63)=\right.$ $9.4, p<.003$ ] and between phonemically similar and neutral prime pairs $\left[\min F^{\prime}(1,56)=4.79, p<.003\right]$. None of the further comparisons revealed significant differences or interactions.

In the error analysis, only the main effect if lexicality was significant $\left[\min F^{\prime}(1,102)=23.71, p<.001\right]$. When separate analyses were conducted for words and pseudowords, respectively, none of the main effects or interactions turned out to be significant.

The results of the analysis showed no advantage for either graphemic or phonemic similarity over the unrelated condition. The only significant differences were obtained when the experimental conditions were compared to the neutral prime condition. Significantly faster responses with and-like primes were observed by de Groot et al. (1982). They attributed such effects to the reduced prime processing induced by the repeated presentation. The im-

Table 2

Mean Naming Latencies (in Milliseconds), Standard Deviations, and Error Rate as a Function of Lexicality and Frequency in Experiment 2

\begin{tabular}{|c|c|c|c|c|c|c|c|c|c|c|c|c|}
\hline \multirow[b]{3}{*}{ Condition } & \multicolumn{6}{|c|}{ Words } & \multicolumn{6}{|c|}{ Pseudowords } \\
\hline & \multicolumn{3}{|c|}{ High-Frequency } & \multicolumn{3}{|c|}{ Low-Frequency } & \multicolumn{3}{|c|}{ High-Frequency } & \multicolumn{3}{|c|}{ Low-Frequency } \\
\hline & $M$ & $S D$ & $\%$ Error & $M$ & $S D$ & $\%$ Error & $M$ & $S D$ & $\%$ Error & $M$ & $S D$ & \% Error \\
\hline 1 & 586 & 78 & 4.09 & 589 & 75 & 3.30 & 620 & 84 & 5.00 & 648 & 86 & 4.77 \\
\hline 2 & 578 & 68 & 2.16 & 589 & 68 & 2.61 & 641 & 86 & 6.14 & 656 & 82 & 8.07 \\
\hline 3 & 579 & 68 & 2.84 & 594 & 71 & 3.64 & 632 & 82 & 5.57 & 651 & 83 & 6.63 \\
\hline 4 & 559 & 74 & 1.59 & 564 & 71 & 2.05 & 610 & 84 & 4.77 & 637 & 92 & 5.91 \\
\hline
\end{tabular}


plication is that and should not be used as the baseline for comparisons. The failure to find a priming effect in Experiment 2 could have occurred because prime identification, though reduced, was still possible. (The prompts introduced randomly throughout the trials revealed that subjects could recall both prime and target, with prime identification less than perfect but still high.) As noted, a number of studies have shown that graphic priming does not occur consistently unless the identification of the prime is reduced to a minimum.

\section{DISCUSSION}

The experiments reported here were conducted to examine the use of phonological information in the naming of English words. A priming technique was used under normal presentation conditions (Experiment 1 ) and in a forward masking paradigm (Experiment 2). In neither experiment did we find a phonological or even a graphemic priming effect. These results coincide with those found by Martin and Jensen (1988) with the lexical decision task. These investigators repeated and extended Hillinger's (1980) study but failed to obtain significant phonological or graphemic priming effects.

The following questions remain: Why did the priming effect not occur for words, and why did the priming effect for pseudowords that was observed in Experiment 1 not persist under the masking condition of Experiment 2? The finding in Experiment 1, that the pseudowords were named significantly faster than the unrelated controls, together with the finding that there was no significant difference between the two experimental situations, might be reason to believe that some priming effects were obscured for the word targets. Even though the difference between highand low-frequency pseudowords was significant (high-frequency pseudowords were named significantly faster than low-frequency pseudowords were), the sign of the priming effect was the same. The latter result might be taken as evidence of a phonological priming effect for pseudowords. At this point, it might be argued that, since priming effects in English are not as strong as they are in some other languages (e.g., Serbo-Croatian), and since they depend on a number of lexical and nonlexical variables, the lack of all the necessary controls (whatever their nature) might have lessened the power of possible outcomes for words. As for the absence of priming under masking, it might be argued that since prime identification was hindered but the primes were still visible, the subjects might have devoted more attention toward identifying the primes, thus inhibiting the possible facilitatory effects that would have occurred automatically had the subjects not been aware of the primes.

Another finding deserves comment. In both experiments, word frequency was not a significant factor. Although low-frequency words were consistently named more slowly, the difference never exceeded the level of significance. Similar results were reported by Evett and Humphreys (1981) and Forster and Davis (1984) for the lexical decision task. Paap, Newsome, McDonald, and Schvaneveldt (1982) also reported a lack of significant difference between high- and low-frequency words in the naming task. The latter authors suggested that the lack of a wordfrequency effect in naming should be considered proof of the use of a nonlexical route in naming. Such a route leads to faster responses for most of the low-frequency words; but the improvement is never large enough to make response times for high- and low-frequency words equal, and thus a nonsignificant difference between them remains.

Contrary to high- and low-frequency words, for which there was no frequency effect, pseudowords differed significantly in both Experiment 1 and Experiment 2 . It should be emphasized that pseudowords essentially cannot be of either high or low frequency, since they lack lexical representations. "High" or "low" frequency for pseudowords means only that a particular pseudoword was derived from either a high- or low-frequency word. Therefore, all other things being equal, there should not be any frequency effect for pseudowords. It is possible that pseudowords differed significantly in their pronounceability, or in more or less usual letter combinations. It is also possible that their "summed positional frequencies" were significantly different. This measure, whose effectiveness was demonstrated by Mason (1975), is based on the single letter frequency of each letter (Mayzner \& Tresselt, 1965) in printed English words, taking into account word length and serial position. Katz (1977) reported that adult readers were sensitive to the regularities of the positions of single letters. If "low-frequency" pseudowords had significantly lower serial position frequency, that might have caused the significant difference in naming latencies for high- and low-frequency pseudowords.

Altogether, it seems that the discussion about both graphemic and phonological priming in naming is far from being closed. Letter-to-sound correspondence in English is neither unique nor simple, and many restrictions are required for the priming effects to occur systematically. Only better control of experimental variables can help us understand the processes that underlie word recognition and word naming.

\section{REFERENCES}

CoLomвo, L. (1986). Activation and inhibition with orthographically similar words. Journal of Experimental Psychology: Human Perception \& Performance, 12, 226-234.

de Groot, A. M. B., Thomassen, A. J. W. M., \& Hudson, P. T. W. (1982). Associative facilitation of word recognition as measured from a neutral prime. Memory \& Cognition, 10, 358-370.

EvetT, L. J., \& Humphreys, G. W. (1981). The use of abstract graphemic information in lexical access. Quarterly Journal of Experimental Psychology, 33A, 325-350.

FORSTER, K. I. , \& DAVIS, C. (1984). Repetition priming and frequency attenuation in lexical access. Journal of Experimental Psychology: Learning, Memory, \& Cognition, 10, 680-698.

Hillinger, M. L. (1980). Priming effects with phonemically similar words: The encoding-bias hypothesis reconsidered. Memory \& Cognition, 8, 115-123.

Humphreys, G. W., EvetT, L. J., \& Taylor, D. E. (1982). Automatic phonological priming in visual word recognition. Memory \& Cognition, 10, 576-590.

Humphreys, G. W., Evett, L. J., Quinlan, P. T., \& Besner, D. (1987). Orthographic priming: Qualitative differences between priming from identified and unidentified primes. In M. Coltheart (Ed.), Attention and performance XII (pp. 105-125). Hillsdale, NJ: Erlbaum.

KATZ, L. (1977). Reading ability and single letter redundancy. Journal of Educational Psychology, 69, 653-659.

KučERA, H., \& FrANCIS, W. (1967). Computational analysis of presentday American English. Providence, RI: Brown University Press.

Lukatela, G., Feldman, L. B., Turvey, M. T., Carrelo, C., \& KATZ, L. (1989). Context effect in bi-alphabetical word perception. Journal of Memory \& Language, 28, 214-236.

Lukatela, G., \& TuRvey, M. T. (1990). Phonemic similarity effects and prelexical phonology. Memory \& Cognition, 18, 128-152.

lukatela, G., Turvey, M. T., Feldman, L. B., Carrelo, C., \& KATZ, L. (1989). Alphabet priming in bi-alphabetical word perception. Journal of Memory \& Language, 28, 237-254.

MARTin, R. C., \& JenSEN, C. R. (1988). Phonological priming in the lexical decision task: A failure to replicate. Memory \& Cognition, 16, 505-521.

Mason, M. (1975). Reading ability and letter search time: Effects of orthographic structure defined by single-letter positional frequency. Journal of Experimental Psychology: General, 104, 146-166.

MAYZNer, M. S., \& TREsSelt, M. E. (1965). Tables of single-letter and diagram frequency counts for various word-length and letterposition combinations. Psychonomic Monograph Supplements, 1 (No. 2), 13-32.

PaAP, K. R., Newsome, S. L., McDonald, J. E., \& SchvaneVELDT, R. W. (1982). An activation-verification model for letter and word recognition: The word superiority effect. Psychological Review, 89, 573-594.

(Manuscript received March 17, 1990.) 